\section{Synthesis of nanomaterials using expired medicines: an eco-friendly option}

\author{
Anal K. Jha, ${ }^{1}$ Kamal Prasad ${ }^{2}$ \\ 'University Department of Chemistry, \\ T.M. Bhagalpur University, Bhagalpur; \\ ${ }^{2}$ Centre for Applied Physics, Central \\ University of Jharkhand, Brambe, Ranchi, \\ India
}

\section{Abstract}

Expired medicines are a burden to the environment. In this paper, a novel method is suggested to reutilize expired medicines in order to assess the possibilities of synthesizing a variety of nanomaterials. To this end, expired flouroquinolone (norfloxacin) and tinidazole combinations were used to synthesize metal $(\mathrm{Au})$, oxide $\left(\mathrm{ZrO}_{2}\right)$ and chalcognide (CdS) nanoparticles using for the first time a green chemistry approach. $\mathrm{Au}, \mathrm{ZrO}_{2}$ and $\mathrm{CdS}$ nanoparticles are available in convenient sizes of $6 \mathrm{~nm}$, $26 \mathrm{~nm}$ and $18 \mathrm{~nm}$, respectively, and remain stable for at least six months. This novel procedure is possible thanks to their molecular organization and elements. The inclusion of a fluorine atom in a drug molecule may influence both the disposition of the drug and its interaction with its pharmacological target; for example, the effects of fluorine substitution on the inter- and intra-molecular forces that affect binding of ligands. The presence of sulfur in the tinidazole molecules may also have contributed towards synthesis through proton withdrawal. The nanomaterials synthesized in this way were characterized using X-ray diffraction analysis and transmission electron microscopy to identify the formation of the desired nanoparticles. This single-step green approach is very convenient, simple and can be extended to synthesize a variety of nanomaterials that might find new technological and pharmaceutical applications.

\section{Introduction}

Because of their unique chemical and physical properties that differ from those of bulk materials, nanostructured materials have attracted considerable attention for their exponential promise of application in almost all walks of life. The synthesis of a variety of nanoparticles has been reported using various methods, such as intensive ball milling, plasma arc, flame combustion, sol-gel, wet-chemical, hydrothermal, solvothermal, emulsion pre- cipitation, membrane-template, microbe and plant assisted biosynthesis, etc. Furthermore, medicines in their various forms have become an indispensable part of our lives. For as long as we have used chemicals for the treatment of ailments, trace levels of these substances have been off-loaded into water. There is a high price to pay for pharmaceutical pollution, a price that is paid in many different ways, such as contamination of surface water and underground aquifers. Furthermore, over recent years, there has been a wonderful convergence of nanotechnology and pharmaceutical science. Recently, there have been reports of synthesis of different nanomaterials, e.g. Ag and $\mathrm{TiO}_{2},{ }^{1} \mathrm{Gd}_{2} \mathrm{O}_{3}{ }^{2}$ and $\mathrm{WO}_{3},{ }^{3}$ using probiotic spore tablets while $\mathrm{Ag}, \mathrm{Pd}, \mathrm{Au}$ and $\mathrm{Pt}$ nanospheres, nanowires and nanorods have been synthesized using vitamin $\mathrm{B}_{2}$ (Riboflavin). ${ }^{4,5}$

To do this, different nanomaterials have been synthesized using expired medicines. This study aims to provide a green protocol to synthesize different nanomaterials using a green chemistry approach. Green chemistry is the design, development and implementation of chemical products and the process of reducing or eliminating the use and generation of substances hazardous to human health and the environment. ${ }^{5,6}$ Strategies to address mounting environmental concerns with current approaches include the use of environmentally benign solvents, biodegradable polymers, and non-toxic chemicals. The expired medicines (with respect to human physiological/therapeutic parameters) as such are soft chemicals that still maintain their entity and characteristics.

With this objective in mind, this study used expired medicines of the quinolone group of an antibiotic and tinidazole combination (Norflox$\mathrm{TZ}$, an anti-diahorrea drug commonly used in India). Norfloxacin is a synthetic flouroquinolone class antibiotic usually prescribed for the treatment of urinary tract infections. Flouroquinolones are gaining popularity as important antibacterial agents in veterinary medicine because of their broad spectrum antimicrobial activity. ${ }^{7}$ Quinolones are active against gram negative and gram-positive bacteria in vitro ${ }^{8}$ as well as against trimethoprim/sulfonamide resistant microbes. ${ }^{9}$ Functionally, quinolones are synthetic antibiotics that act by inhibiting DNA gyrase and topoisomerase IV in susceptible bacteria. The original quinolones have modest activity against Enterobacteriaceae and some other facultative gram-negative bacteria only. Tinidazole is an anti-protozoal agent which is a structural analog of metronidazole. It was recently approved by the US Food and Drug Administration for the treatment of trichomoniasis, giardiasis, amebiasis and amebic liver abscess.

Therefore, 4-month expired Norflox-TZ tablets were used to assess for the first time
Correspondence: Kamal Prasad, Centre for Applied Physics, Central University of Jharkhand, C.T.I. Campus, Brambe, Ranchi, 835205, India. Tel. +91.9431690360 .

E-mail: k.prasad65@gmail.com

k_prasad65@yahoo.co.in

Key words: nanoparticles, nanomaterials, expired medicine, green synthesis, green chemistry.

Contributions: AKJ, study conception and design, drafting and revising the article for important intellectual content; KP, analysis and interpretation of data, revising the article critically for important intellectual content, and final approval of the version to be published.

Conflict of interests: the authors have no potential conflict of interests.

Received for publication: 31 August 2011.

Revision received: 15 March 2012.

Accepted for publication: 4 April 2012.

This work is licensed under a Creative Commons Attribution NonCommercial 3.0 License (CC BYNC 3.0).

(C) Copyright A.K. Jha and K. Prasad, 2012 Licensee PAGEPress, Italy

Nanotechnology Development 2012; 2:e7 doi:10.4081/nd.2012.e7

their ability to synthesize a variety of nanomaterials, such as metal $(\mathrm{Au})$, oxide $\left(\mathrm{ZrO}_{2}\right)$ and chalcognide (CdS), with the belief that our effort might not only help in controlling the menace of pollution, but could also open up ways for the pharmaceutical companies to recycle their waste drugs by synthesizing nanomaterials.

\section{Materials and Methods}

\section{Preparation of broth from expired drug (Norflox-TZ)}

Four-month expired Norflox-TZ (500 mg) tablets were dissolved slowly in $100 \mathrm{~mL}$ sterile distilled water. To this was added $5 \mathrm{~mL} \mathrm{~N} / 20$ $\mathrm{HCl}$ to ensure a better degree of dissolution through gentle heating over a steam bath of up to $40^{\circ} \mathrm{C}$ until a light yellow color appeared in the conical flask. Then, $25 \mathrm{~mL}$ of this source broth was diluted 4 times by the addition of distilled water. This source solution $(\mathrm{pH}=3)$ was used to synthesize nanomaterials.

\section{Biosynthesis of gold nanoparticles}

A $20 \mathrm{~mL}$ solution of chloroauric acid $(0.25$ molar) was added to the warm broth solution and the pH was gradually shifted to 7 and finally to 9 at which point the particles tend to turn 
deep brown/scarlet in color. This solution was allowed to cool down at room temperature for 2 $\mathrm{h}$ when the precipitation of nanoparticles was completed leaving a ruby red supernatant at the top.

\section{Biosynthesis of $\mathrm{ZrO}_{2}$ nanoparticles}

Twenty $\mathrm{mL}$ of $0.25(\mathrm{M}) \mathrm{ZrO}(\mathrm{OH})_{2}$ slurry was charged to the expired drug broth solution maintaining the $\mathrm{pH}$ value of 6 . The solution was then heated up to $80^{\circ} \mathrm{C}$ for 20 min until a milky white fluffy mass started to appear. This slowly tends to settle down. This solution was then allowed to cool and, in turn, segregate between the fluffy mass and the clear supernatant overnight.

\section{Biosynthesis of CdS nanoparticles}

Twenty $\mathrm{mL}$ of $0.25(\mathrm{M}) \mathrm{CdCl}_{2}$ solution was purged with $\mathrm{H}_{2} \mathrm{~S}$ and this was heated for $10 \mathrm{~min}$ over a water bath in order to expel the surplus hydrogen sulfide. This was charged to the broth solution shifting the $\mathrm{pH}$ to 4 . Immediately, the $\mathrm{CdS}$ appears fluffy and on progressive heating the $\mathrm{pH}$ further shifted to 5 leading to a successful transformation as indicated by the yellowish/orange color of the broth and the deposition of the precipitate at the bottom.

\section{Characterization}

The formation of $\mathrm{Au}, \mathrm{ZrO}_{2}$ and $\mathrm{CdS}$ NPs was checked by an X-ray diffraction (XRD) technique using an X-ray diffractometer (Rikagu Miniflex, Tokyo, Japan) with $\mathrm{CuK}_{\alpha}$ radiation $\left(\lambda=1.5406 \AA\right.$ ) between $15^{\circ}$ and $75^{\circ}$ angles. Transmission electron microscopy (TEM) micrographs and selected area diffraction (SAED) patters of $\mathrm{Au}, \mathrm{ZrO}_{2}$ and $\mathrm{CdS}$ NPs were obtained using a Bruker transmission electron microscope. The specimen was suspended in distilled water, dispersed ultrasonically to separate individual particles, and one or two drops of the suspension were deposited onto holey carbon coated copper grids.

\section{Results}

Figure 1 shows the indexed XRD profiles of $\mathrm{Au}, \mathrm{ZrO}_{2}$ and $\mathrm{CdS}$ NPs at room temperature. The XRD patterns showed the presence of broad peaks. The broad peaks indicate either particles of very small crystallite size or that particles are semi-crystalline in nature. The peaks of the XRD-patterns were indexed and cell parameters were determined with a standard computer program POWD using experimental $d$-values of peaks on different crystal systems. The least squares regression fit to diffraction data yielded the lattice parameters. The lattice parameters as obtained for $\mathrm{Au}, \mathrm{ZrO}_{2}$

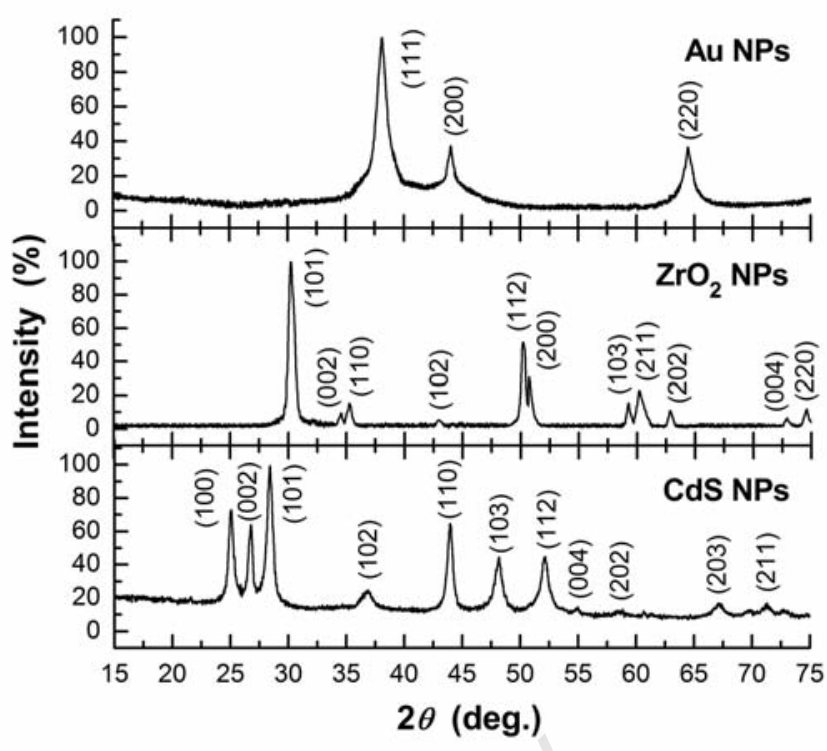

Figure 1. Indexed $\mathrm{X}$-ray diffraction patterns of $\mathrm{Au}, \mathrm{ZrO}_{2}$ and $\mathrm{CdS}$ nanoparticles at room temperature.

and CdS NPs are shown in Table 1. The crystal systems and cell parameters are in very good agreement with the reports in literature (JCPDS - International Centre for Diffraction Data ${ }^{\circledR}$ - file numbers: $65-2870,79-1769,80$ 0006. http//www.icdd.com/index.htm). The criterion adopted for evaluating the rightness, reliability of the indexing and the structure of NPs was $\left.\sum \Delta d=\sum\left(d_{o b s}-d_{\text {calc }}\right)\right\}$ found to be a minimum. The apparent particle sizes of the prepared nanoparticles were estimated by analyzing the X-ray diffraction peak broadening using the Debye-Scherrer formula: $D=0.89 \lambda / \beta_{1 / 2} \cos \theta$ where $\beta_{1 / 2}$ is the full width at half maximum. Apparent particle sizes are listed in Table 1.

Figure 2 shows the TEM micrographs and SAED patterns (insets) of the $\mathrm{Au}, \mathrm{ZrO}_{2}$ and CdS NPs being formed using expired NorfloxTZ tablets. The micrographs clearly illustrate individual nanoparticles as well as a very few agglomerates. Particles were measured along their largest diameter. The particles were found to be of different sizes and almost spherical in shape (Table 1). The difference in particle size may possibly be due to the fact that the nanoparticles are being formed at different times. The sizes of different nanoparticles estimated using the Scherrer technique agree quite well with the size estimated by TEM analysis (Table 1). Furthermore, combinations of spotty patterns along with concentric Scherrer rings are clearly visible in the SAED patterns, showing that the nanoparticles all have different possible orientations. Also, it was observed that the crystal structures as observed in the SAED patterns are in close agreement with $\mathrm{XRD}$ results.
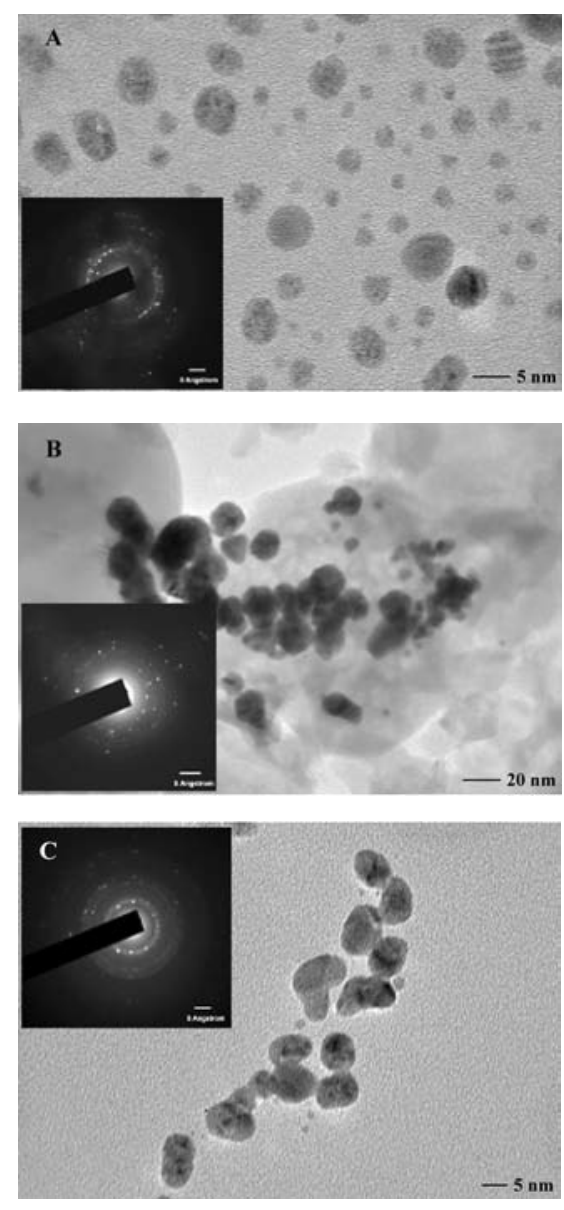

Figure 2. Transmission electron microscopy photographs and selected area diffraction patterns (insets) of (A) $\mathrm{Au},(\mathrm{B}) \mathrm{ZrO}_{2}$ and (C) CdS NPs synthesized using expired NorfloxTZ. 


\section{Discussion}

Because of their fundamental molecular compositions, both the constituents (norfloxacin and tinidazole) are capable of undertaking redox reactions. The Ketonic group present in the quinolone nucleus and the additional fluorine atom in the molecule are clear indications of its redox agility. Furthermore, production of a zweitter-ion (Figure 3A) makes the milieu amenable for a desired nanosynthesis. Similarly, the $S=0$ group could also act as one that withdraws protons in the tinidazole compound (Figure 3B). Fluorine substitution can alter the chemical properties, disposition and biological activity of drugs..$^{10}$ Many fluorinated compounds are currently widely used in the treatment of a variety of diseases. These include antidepressants, anti-inflammatory agents, anti-malarial drugs, anti-psychotics, antiviral agents, steroids and general anesthetics. ${ }^{11}$ The chemistry and medicinal chemistry of fluoroorganic compounds and drugs have been reviewed. ${ }^{10,12-14}$ The inclusion of a fluorine atom in a drug molecule can influence both the disposition of the drug and its interaction with its pharmacological target. For example, the effects of fluorine substitution on the inter- and intra-molecular forces that affect binding of ligands to cholinergic and adrenergic receptors, and thus introduce receptor subtype selectivity, are now well understood. ${ }^{15-17}$ The replacement of a hydrogen atom or hydroxyl group by a fluorine atom is a strategy being widely used in drug development to alter biological functions. Although it is generally thought that fluorine for hydrogen substitution causes minimal steric effects at receptor sites, the actual van der Waals radius of fluorine (1.47 $\AA$ ) lies between that of oxygen $(1.57 \AA)$ and hydrogen (1.2 $\AA$ ). Despite the fact that fluorine has a greater size than hydrogen, several studies have demonstrated that it is reasonable to believe that hydrogen mimics and exerts only a minor steric demand at receptor sites, at least for mono-functional analogs. ${ }^{12}$

Chemically, norfloxacin is 1-ethyl-6-fluoro1,4-dihydro-4-oxo-7-(1-piperazinyl)-3-quinoline carboxylic acid. It differs from other quinolones by having a fluorine atom at the 6 position and a piperazine moiety at the 7 position. Recent infrared spectroscopic study involving free norfloxacin exhibits very strong bands at 1729 and $1619 \mathrm{~cm}^{-1}$ which are assigned to the stretching vibration of the carboxylic $v(\mathrm{COOH})$ and the pyridone stretch $v(\mathrm{C}=0) .{ }^{18,19}$ These bands disappear in the complexes that simply imply the involvement of the carboxylic group and the carbonyl oxygen atom in the interaction with metal ions. The carboxylato group can act as unidentate, bidentate or as bridging ligand, and the frequency separation $\left[\Delta v=v_{a s}\left(\mathrm{COO}^{-}\right)-v_{s}\left(\mathrm{COO}^{-}\right)\right]$ between the asymmetric and symmetric stretching of this group can be made to distinguish between these binding states. ${ }^{20,21}$ Furthermore, tinidazole (chemically 1 [2(ethylsulfonyl)ethyl]-2methyl-5-nitroimidazole) as well as metronidazole and ornidazole are 5 nitroimidazole. All 5-nitroimidazoles are synthetic drugs. The hydrolysis of tinidazole followed apparent first-order kinetics in most of the conditions studied. It was hydrolytically most stable at pH 4.0-5.0. It was demonstrated that at least one of the reacting partners contributing to the transition state had a charge of zero in the major degradation pathway at various $\mathrm{pH}$ values. The dominant reactions were tinidazole $+\mathrm{OH}^{-}$at $\mathrm{pH}=7$ and tinidazole $+\mathrm{H}_{2} \mathrm{O}$ at a $\mathrm{pH}$ of 4.5. In more acidic conditions, the reaction tinidazole $+\mathrm{H}^{+}$and/or [tinidazole $+\mathrm{H}]^{+}+\mathrm{H}_{2} \mathrm{O}$ takes place, but the existence of [tinidazole $+\mathrm{H}]^{+}+\mathrm{H}^{+}$could not be excluded nor corroborated. A mechanism for the alkaline hydrolysis was suggested that involved a proton transfer from tinidazole to the hydroxide ion and the formation of ethyl vinyl sulfone. The reaction may occur in either a stepwise or a concerted manner with activation energy of the hydrolysis reaction, which was determined to be $120-130 \mathrm{~kJ} / \mathrm{mol} .^{22}$ Altogether, the broth solution provides the requisite ambience in terms of energy required for the synthesis of a variety of nanoparticles. Furthermore, stability of the synthesized materials of up to six months or even more (in the case of metal, oxide and chalcognide in this paper) confers an additional advantage compared to existing protocols. Hence, the results consolidate the idea that also expired medicines can participate in nanotransformations.

Table 1. Summary of parameters obtained from structural and microstructural studies.

\begin{tabular}{|c|c|c|c|}
\hline Parameters & Au NPs & $\mathrm{ZrO}_{2} \mathrm{NPs}$ & CdS NPs \\
\hline Crystal system & Cubic (fcc) & Tetragonal & Hexagonal \\
\hline $\begin{aligned} \text { Cell edge length }(a) \\
\\
(c)\end{aligned}$ & $\begin{array}{c}4.076 \AA \\
-\end{array}$ & $\begin{array}{l}3.252 \AA \\
5.212 \AA\end{array}$ & $\begin{array}{l}4.119 \AA \\
6.681 \AA\end{array}$ \\
\hline Apparent particle size (X-ray) & $6 \mathrm{~nm}$ & $26 \mathrm{~nm}$ & $17 \mathrm{~nm}$ \\
\hline Particle size (TEM) & $2-10 \mathrm{~nm}$ & $8-52 \mathrm{~nm}$ & $3-18 \mathrm{~nm}$ \\
\hline
\end{tabular}

TEM, transmission electron microscopy; NPs, nanoparticles.<smiles>CCn1cc(C(=O)[O-])c(=O)c2cc(F)c(N3CC[NH+]CC3)cc21</smiles>

B<smiles>CCS(=O)(=O)CCn1c([N+](=O)[O-])cnc1C</smiles>

Figure 3. Chemical structure of (A) norfloxacin zwetter-ion and (B) tinidazole.

Furthermore, this suggests that nano $\mathrm{Au}, \mathrm{ZrO}_{2}$ and $\mathrm{CdS}$ sol and particles could be potentially effective to defend against bacterial or fungal attacks. However, we are now aiming to suitably modulate our experimental approach to achieve a better shelf life for all these and other nanomaterials, and our research in this direction is ongoing.

\section{Conclusions}

The synthesis of different nanoparticles might have resulted from the production of norfloxacin zweitter-ion and tinidazole together with its steady kinetics, a factor responsible for the desired nanosynthesis. The present method is a low cost green approach capable of producing varieties of nanomaterials using different expired medicines. This approach consolidates the idea that also expired medicines can play a part in nanotransformation. Also, this synthetic method might be a step towards controlling the menace of pollution and open a way for the pharmaceutical companies to recycle their waste medicines/drugs by synthesizing nanomaterials.

\section{References}

1. Jha AK, Prasad K. Biosynthesis of metal and oxide nanoparticles using Lactobacilli from yoghurt and probiotic spore tablets. Biotechnol J 2010;5:285-91.

2. Jha AK, Prasad K, Kulkarni AR. Synthesis 
of $\mathrm{Gd}_{2} \mathrm{O}_{3}$ nanoparticles using Lactobacillus sp.: a novel green approach. Int J Green Nanotechnol Phys Chem 2010;2:P31-8.

3. Prasad K, Jha AK, Kulkarni AR. Probiotic Lactobacillus adds $\mathrm{WO}_{3}$ in its nanomenu!. J Bionanosci 2010;4:99-103.

4. Nadagouda MN, Varma RS. Green synthesis of Ag and Pd nanospheres, nanowires, and nanorods using vitamin $\mathrm{B}_{2}$ : catalytic polymerisation of aniline and pyrrole. $\mathrm{J}$ Nanomater 2008;2008:1-9.

5. Nadagouda MN, Varma RS. Green and controlled synthesis of gold and platinum nanomaterials using vitamin $\mathrm{B}_{2}$ : densityassisted self-assembly of nanospheres, wires and rods. Green Chem 2006;8:516-8.

6. Anastas PT, Warner JC. Green chemistry: theory and practice. Oxford, UK: Oxford University Press; 1998.

7. Park SC, Yun HI, Oh TK. Comparative pharmacokinetic profiles of two norfloxacin formulations after oral administration in rabbits. J Vet Med Sci 1998;5: 661-3.

8. Wolfson JS, Hooper DC. The fluroquinolones: structures, mechanism of action and resistance and spectra of activity in vitro. Antimicrob Agents Chemother 1985;28:581-6.
9. Preheim L, Cuevas T, Roccaforte J, et al. Oral use of ciprofloxacin in the treatment of elderly patients with complicated urinary tract infections due to trimethoprim/ sulfamethoxazole-resistant bacteria. Am J Med 1987;82:295-7.

10. Kirk KL, Filler R. Recent advances in the biomedicinal chemistry of fluorine containing compounds. In: Ojima I, McCarthy JR, Welch JT (eds). Biomedical frontiers of fluorine chemistry - Symposium series, vol. 639. Washington, DC: American Chemical Society; 1996. pp 1-24.

11. Dollery C. Therapeutic drugs. Edinburgh, UK: Churchill Livingstone; 1999.

12. O'Hagan D, Rzepa HS. Some influences of fluorine in bioorganic chemistry. Chem Commun 1997;7:645-52.

13. Resnati G. Aspects of the medicinal chemistry of fluoroorganic compounds. Part I. Farmaco 1990;45:1043-66.

14. Resnati G. Aspects of the medicinal chemistry of fluoroorganic compounds. Part II. Farmaco 1990;45:1137-67.

15. Bravo P, Resnati G, Angeli P, et al. Synthesis and pharmacological evaluation of enantiomerically pure 4-deoxy-4-fluoromuscarines. J Med Chem 1992;35:3102-10.

16. Lu SF, Herbert B, Haufe G, et al. Syntheses of (R)- and (S)-2- and 6-fluoronorepinephrine and (R)- and (S)-2- and 6-fluoroepinephrine: effect of stereochemistry on fluorine induced adrenergic selectivities. J Med Chem 2000;43:1611-9.

17. Tewson TJ, Stekhova S, Kinsey B, et al. Synthesis and biodistribution of R- and Sisomers of [18F]- fluoropropranolol, a lipophilic ligand for the beta-adrenergic receptor. Nucl Med Biol 1999;26:891-6.

18. Silverstein RM, Bassler GC, Morril TC. Spectroscopic identification of organic compounds. $5^{\text {th }}$ ed. New York: Wiley; 1991.

19. Sadeek SA, El-Did Amony AM, El-Shwiniy WH, Zordok WA. Uranium (VI) and zirconium (IV) of the second-generation quinolone antimicrobial drug norfloxacin: structure and biological activity. J Argentine Chem Soc 2009;97:51-76.

20. Nakamoto K. Infrared and Raman spectra of inorganic and coordination compounds. $4^{\text {th }}$ ed. New York: Wiley; 1986.

21. Salo J-PK, Hydrolysis of tinidazole. Dissertation. University of Helsinki; 2003.

22. Eddy NO, Stoyanov SR, Ebenso EE. Fluoroquinolones as corrosion inhibitors for mild steel in acidic medium; experimental and theoretical studies. Int $\mathrm{J}$ Electrochem Sci 2010;5:1127-50. 